\title{
DEMOCRACIA, PARTICIPAÇÃO E GESTÃO EDUCACIONAL: DIÁLOGOS NOS ESCCRITOS FREIREANOS
}

\author{
DEMOCRACY, PARTICIPATION AND EDUCATIONAL MANAGEMENT: \\ DIALOGUES IN FREIREAN WRITINGS
}

Katia Cristina Custódio Ferreira Brito

Doutora em Educação - UFSCAR

Universidade Federal do Tocantins - UFT

Palmas, Tocantins - Brasil

katiacristina@mail.uft.edu.br

Ângela Noleto da Silva Doutoranda no Programa de Pós-Graduação em Educação/PPGE/UNB

Mestre em Educação - UFG

Universidade Federal do Tocantins

Palmas, Tocantins - Brasil

angelanoleto@uft.edu.br

Ana Gabriela Ferreira Brito

Mestranda em Ensino - UFT

Palmas, Tocantins - Brasil

anagfbrito@gmail.com

\begin{abstract}
Resumo: Este artigo propõe uma análise dos conceitos de participação e democracia apresentados por Paulo Freire em seus diversos escritos. O objeto da pesquisa consiste no postulado teórico de Paulo Freire no que se refere a esses conceitos. A questão formulada visa identificar como se apresentam e se relacionam na obra freireana os conceitos de democracia e participação e em que medida possibilitam sua reconstrução em tempos de retorno a práticas e regulamentações conservadoras no âmbito educacional. Com objetivos exploratórios, abordagem qualitativa e estudos bibliográficos, identificou-se nos escritos do autor uma sequência de análises que propicia o entendimento da relação entre os conceitos e a possibilidade de diálogo, de compreensão do outro e de recondução para novos caminhos. Observam-se reflexões que explicitam a democracia como caminho do educar e do ser mais. Ademais, concluiu-se que tais conceitos não possuem valor em si só, mas na prática cotidiana.
\end{abstract}

Palavras-chave: democracia; gestão escolar; participação; Paulo Freire

\begin{abstract}
The text proposes an analysis of the concepts of participation and democracy presented by Paulo Freire in his various writings. The object of the research consists of Paulo Freire's theoretical postulate regarding these concepts. The question formulated aims to identify how the concepts of democracy and participation are presented and related in Paulo Freire's work, and to what extent they enable their reconstruction in times of return to conservative educational practices and regulations. With exploratory objectives, qualitative approach and bibliographic studies, a sequence of analyzes was identified in the author's writings that make it possible to understand the relationship between the concepts and the possibility of dialogue, the understanding of the other and the renewal of new paths. There are reflections that explain democracy as a way of educating and being more. In addition it is concluded that such concepts do not have value in themselves but in the daily practice.
\end{abstract}

Keywords: democracy; school management; participation; Paulo Freire.

\section{Para citar - (ABNT NBR 6023:2018)}

BRITO, Katia Cristina Custódio Ferreira; SILVA, Ângela Noleto da; BRITO, Ana Gabriela Ferreira. Democracia, participação e gestão educacional: diálogos nos escritos freireanos. Eccos - Revista Científica, São Paulo, n. 57, p. 1-10, e15797, abr./jun. 2021. Disponível em: https://doi.org/10.5585/eccos.n57.15797. 


\title{
Introdução
}

As obras de Paulo Freire se revestem de grande importância para a análise dos conceitos de democracia e de participação. Não só no Brasil, mas em âmbito mundial, é incomum desenvolver estudos e pesquisas relativas aos espaços democráticos de participação e de educação sem buscar no autor referenciado fundamentos teóricos e práticos. Em sua extensa obra, a participação popular se destaca como condição para o diálogo. Lima (2009) contextualiza essa realidade explicitando que:

No exercício de resistência à despolitização (e com frequência à privatização) da escola pública, de defesa de uma educação escolar comprometida com os valores do domínio público, com o aprofundamento da democracia e da cidadania, com a igualdade e a justiça, os contributos e os desafios propostos por Paulo Freire são incontornáveis e mais atuais que nunca (LIMA, 2009, p. 90).

Para a realização do presente estudo, desenvolveu-se o exame de obras publicadas por Paulo Freire, em diferentes datas, visando evidenciar a proeminência dos conceitos em estudo e as possibilidades de seu redimensionamento. Tal análise demonstra que as questões referentes à democracia e à participação são recorrentes em seus escritos. Neles, o autor evidencia que a gestão democrática educacional pode contribuir para a ampliação das estruturas democratizantes e favorecer o exercício da participação popular.

Destarte, para que a relação dialógica seja estabelecida, o clima de abertura e de participação deve ser uma condição necessária. Isso quer dizer que essa relação não poderá ser reduzida a um "estar diante" ou a um "estar sobre", será um "estar com", como sujeitos da mudança. Lima (2003) ressalta esse mesmo processo de educação para a emancipação humana e, em consonância com o pensamento de Paulo Freire, o autor esclarece:

\begin{abstract}
Não remeto, portanto, o estudo da participação para o quadro das técnicas de gestão, nem para o domínio das tecnologias pedagógicas, antes a entendo por referência a um projeto político democrático, como afirmação de interesses e vontades, enquanto elemento limitativo e mesmo inibidor da afirmação de certos poderes, como elemento de intervenção nas esferas de decisão política e organizacional, fator quer de conflitos, quer de consensos negociados. Por isso se rejeita uma concepção imanentista de participação, admitindo-se a não-participação, e se orienta o seu estudo na perspectiva de um fenômeno social e político que, enquanto tal, e dadas as suas repercussões em termos de poder, não é um pressuposto, ou um dado mais ou menos omnipresente (LIMA, 2003, p. 71).
\end{abstract}

\section{Democracia e participação: prática da liberdade e contextos de opressão}

Já nos primeiros escritos de Freire, especialmente em "Educação como Prática da Liberdade", obra publicada em 1967, quando o educador ainda estava em exílio no Chile, há denúncias de uma escola que se distanciava da compreensão do conviver e da construção 
coletiva de uma sociedade mais justa. No primeiro capítulo da referida obra, o autor analisa a experiência brasileira abordando diversos temas, todos eles submetidos a um embate de forças em disputa. Freire adverte, no entanto, que a educação possui a tarefa de possibilitar a transitividade crítica, caracterizada pela prática do diálogo e não da polêmica.

Esta posição transitivamente crítica implica num retorno à matriz verdadeira da democracia. Daí ser esta transitividade crítica característica dos autênticos regimes democráticos e corresponde a formas de vida altamente permeáveis, interrogadoras, inquietas e dialogais, em oposição às formas de vida ' mudas' , quietas e discursivas, das fases rígidas e militarmente autoritárias, como infelizmente vivemos hoje, no recuo que sofremos e que os grupos usurpadores do poder pretendem apresentar como um reencontro com a democracia (FREIRE, 1967, p. 60).

Nessa concepção, democracia é uma forma de vida, antes mesmo de ser uma forma política, cujo intuito é vislumbrar um processo educacional que coloque o ser humano em diálogo constante com o outro, que o predisponha a constantes revisões já que a democracia implica mudança. Freire estabelece a relação entre democracia e educação democrática nestes termos:

Ora, a democracia e a educação democrática se fundam ambas, precisamente, na crença no homem. Na crença em que ele não só pode, mas deve discutir os seus problemas. Os problemas do seu País. Do seu Continente. Do mundo. Os problemas do seu trabalho. Os problemas da própria democracia (FREIRE, 1967, p. 96).

Assim como a democracia, a participação está no bojo das proposições pedagógicas de Paulo Freire. É um fim da educação e, ao mesmo tempo, um elemento da prática educativa. A ação dialógica, base de sua proposta de educação, promove a participação pela sua própria natureza. Diante disso, Freire (2005, p. 127) estabelece que o diálogo é, antes de qualquer coisa, participação: "Participar é discutir, é ter voz, ganhando-a, na política educacional das escolas, na organização de seus orçamentos. Sem uma forte convicção política, sem um discurso democrático cada vez mais próximo da prática democrática, nada disto é possível”.

Em outra importante obra, "Pedagogia do Oprimido", escrita na década de 1960 quando permanecia em exílio no Chile - Freire desvenda a contradição de opressor e de oprimido, ressaltando que a luta pela libertação do ser humano se dá em um processo de reconhecimento do oprimido em relação a si mesmo, com base em sua vocação para ser mais, ao constatar a necessidade de uma práxis que objetive a superação dessas contradições.

Freire $(2014$, p. 73$)$ destacou em seus escritos seminais um processo educativo para a "revolução da realidade opressora", com o objetivo de eliminar a "consciência do opressor introjetada no oprimido", via ação político dialógica: "É, precisamente, quando - às grandes 
maiorias - se proíbe o direito de participarem como sujeitos da história, que elas se encontram dominadas e alienadas" (Ibidem, 2014, p. 73).

Define-se a educação como experiência basicamente dialética da libertação humana, essa condição a torna crucial como norteadora do caminho à liberdade, por isso deve ser realizada como instrumento de transformação social, espaço em que o oprimido desvela o mundo da opressão e se reconhece em processo de permanente libertação.

\begin{abstract}
A verdadeira revolução, cedo ou tarde, tem de inaugurar o diálogo corajoso com as massas. Sua legitimidade está no diálogo com elas, não no engodo, na mentira. Não pode temer as massas, a sua expressividade, a sua participação efetiva no poder. Não pode negá-las. Não pode deixar de prestar-lhes conta. De falar de seus acertos, de seus erros, de seus equívocos, de suas dificuldades (FREIRE, 2014, p. 72).
\end{abstract}

Nesse contexto, a não participação tem a ver com a desigualdade entre os cidadãos e sem participação não há democracia. Ressalte-se que, desde seus primeiros estudos publicados, o autor apresenta uma concepção de participação embasada nos fundamentos da democracia participativa.

Em oposição à educação transformadora e libertadora, o autor apresenta a concepção bancária da educação como instrumento de opressão, situação em que os educandos são apenas sujeitos pacientes, ouvintes que se enchem de retalhos desconectados da realidade, servindo, assim, apenas como depósitos das narrativas dos educadores. Diante dessa concepção, identifica-se aqui a imprescindibilidade de uma educação dialógica que se impõe como caminho para uma educação problematizadora.

O autor compreende o diálogo como caminho por meio do qual o indivíduo ganha significação enquanto ser humano, o que viabiliza o processo de síntese cultural como uma modalidade de educação e de ação com que ele fará frente à força da própria cultura mantenedora das estruturas de poder (FREIRE, 2014).

Esses escritos se revestem de uma contemporaneidade, de um presentismo, os quais merecem destaque, em princípio, por provocarem uma profunda reflexão, a saber: ao "falar sobre", eles provocam um "pensar sobre", como uma forma de ação e de reflexão. Isso acaba evidenciando a prática do diálogo e o comprometimento com a leitura de mundo.

\title{
Democracia e participação: como princípios da gestão escolar
}

No livro "Ação Cultural para a Liberdade" - uma coletânea de artigos escritos entre 1968 e 1974 - Paulo Freire objetiva provocar discussões e reflexões ao abordar a leitura, a alfabetização de adultos e a ação cultural para a libertação. Na obra, o autor já apresenta 
indicações de que sua concepção de participação se refere à atuação ativa em uma prática política em permanente mobilização.

Freire também faz referência à participação política e à participação consciente das grandes massas populares em busca de um novo mundo a ser criado no processo revolucionário.

\begin{abstract}
$\mathrm{Na}$ verdade, porém, esse mundo novo não surge assim. Ele é criado no processo revolucionário que, devendo ser permanente, não se esgota com a chegada da revolução ao poder. A criação desse mundo novo, que jamais deve ser 'sacralizado' , exige a participação consciente das grandes massas populares, a superação da dicotomia trabalho manual - trabalho intelectual e uma forma de educação que não repita a burguesa (FREIRE, 1981, p. 77).
\end{abstract}

Ao longo de seus escritos, o autor apresenta a gestão democrática como eixo de análise e de atuação. Não obstante, não é possível reafirmar esse conceito sem perceber sua estreita relação com os conceitos de participação e de autonomia.

Não devemos chamar o povo à escola para receber instruções, postulados, receitas, ameaças, repreensões e punições, mas para participar coletivamente da construção de um saber, que vai além do saber de pura experiência feito, que leve em conta as suas necessidades e o torne instrumento de luta, possibilitando-lhe transformar em sujeito de sua própria história (FREIRE, 2001, p. 35).

Ressalte-se que esse pensamento está sempre em movimento e dialoga com diversas questões contemporâneas, possibilitando a expressão de elementos norteadores para a construção de uma sociedade mais humana. Esses conceitos são tratados em diferentes obras do autor, em vários documentos da Secretaria Municipal de Educação de São Paulo (SME), publicados durante o período em que Paulo Freire exerceu o cargo de Secretário de Educação.

\footnotetext{
O que significa 'participar' e 'descentralizar' numa administração popular? Os mesmos objetivos estão presentes no discurso de políticos cuja orientação é oposta à nossa. O que nos diferencia deles é o conteúdo que imprimimos a esses princípios e a nossa decisão de não permitir que eles fiquem apenas no terreno das intenções [...] para nós, descentralização e participação dizem respeito ao ato de decidir. O equívoco que mais frequentemente se comete em relação a essas questões é descentralizar a execução das tarefas e manter as decisões centralizadas (SME/SP, 1992, p. 65-66).
}

Paulo Freire, na década de 1990, enquanto gestor, apresentou uma concepção de participação delineada e construída ao longo de sua trajetória, desde suas primeiras obras. Se se considerar que a essência do pensamento de Freire se delineia em um de seus conceitos fundantes, a dialogicidade, pode-se compreender que essa prática só ocorreria em uma perspectiva de participação em que, essencialmente, a dimensão deliberativa se apresentasse. Assim, participar implica decidir. Não é por menos que o autor "[...] se destaca como defensor de concepções democráticas e participativas de uma organização como prática da liberdade, 
isto é, de organizações autônomas e autogovernadas, arenas indispensáveis à democracia política, social, econômica, cultural, etc.” (LIMA, 2009, p. 69).

No relato da experiência vivida como gestor, Paulo Freire apresenta o período em que foi Secretário de Educação no município de São Paulo (1989-1991), no governo da prefeita Luíza Erundina. Por meio de entrevistas concedidas durante os dois anos em que permaneceu à frente da Secretaria de Educação, o autor relata o investimento em quatro objetivos descritos no documento oficial "Construindo a Educação Pública Popular” (SME/SP, 1989, p. 7).

Tal documento é composto por uma carta de intenções, na qual se descreve o trabalho a ser realizado na rede municipal de educação. Ele se constitui como um texto preliminar para a construção coletiva de um Regimento Comum das Escolas Municipais e uma carta de apresentação, com o título "Aos que fazem a educação conosco em São Paulo". De acordo com esse documento, “A escola é também um espaço de organização política das classes populares. A escola como um espaço de ensino-aprendizagem será então um centro de debates de ideias, soluções, reflexões, onde a organização popular vai sistematizando sua própria experiência“ (SME/SP, 1989, p. 7).

Analisar a atuação de Paulo Freire como gestor na cidade de São Paulo significa dizer que ele vivenciou o cotidiano de um sistema educacional, com 720.000 alunos da educação básica. Além disso, Freire experienciou a carência de orçamentos públicos, do querer e do poder, permeada por limitações e possibilidades.

No entanto, o déficit não inviabiliza o pensar em uma "[...] escola competente, democrática, séria e alegre" (FREIRE, 2005, p. 19). Além disso, o educador, em sua militância, buscava compreender a prática educativa por meio da natureza essencialmente política. Nessa perspectiva, apresentou sua indignação com a elite brasileira, que "[...] não suporta tudo que cheira povo", que "[...] expulsa as crianças e jovens da escola" (ibidem, 2005, p. 19). Nota-se que o autor se sente estimulado a empreender uma luta pela escola pública, que se constitui com base do diálogo e que se engaja no projeto de transformação social, promovendo a luta democrática (FREIRE, 2005).

É latente, nas diferentes entrevistas que compõem o livro, o exercício permanente da coerência. A atuação político-partidária e administrativa não o distancia da palavra verdadeira outrora pronunciada. Ao ser questionado sobre o papel do educador, Freire apresenta, em suas respostas, uma reflexão sobre o papel do professor e da escola, destacando a atuação docente comprometida, que se apresenta como um conjunto de princípios, posicionamentos e opções que deve nortear sua prática. 
Os objetivos da administração apresentados por ele, na Secretaria de Educação, consistiram em ampliar o acesso dos setores populares às escolas e a sua permanência nelas. Além disso, tinha como foco democratizar o poder pedagógico e educativo, incrementar a qualidade da educação mediante a construção coletiva de um currículo interdisciplinar e a formação permanente do pessoal docente, contribuindo para eliminar o analfabetismo de jovens e adultos.

Os eixos de atuação previstos assinalam o cuidado de fazer o possível para introduzir mudanças democráticas no interior da escola, estimulando a criação e consolidação dos conselhos escolares, com caráter não apenas consultivo, mas deliberativo, possibilitando a vez e a voz de todos os envolvidos no processo educacional.

De forma especial, na gestão freiriana de educação, pensou-se no papel da participação da comunidade e da família de uma forma constante e, sobretudo, decisória. As primeiras iniciativas organizadas, desses espaços coletivos, ocorreram em São Paulo, fato que estimula a compreensão dos caminhos trilhados, dadas as opções feitas pelo autor. A questão formulada por Freire para direcionar a reflexão é: em que medida compreendemos a educação como uma prática política e vivemos a prática educativa em coerência com nossa posição política, desvelando o mundo da opressão?

\section{Democracia e participação: caminhos de esperança}

Na obra "Pedagogia da Esperança", Paulo Freire retoma o conceito de dialogicidade, quase trinta anos depois da escrita de "Pedagogia do Oprimido". Para o autor, esse conceito permeia o processo de transformação e "[...] tem significação, precisamente, porque os sujeitos dialógicos, não apenas conservam sua identidade, mas a defendem e, assim, crescem um com o outro" (FREIRE, 2014, p. 118). Nesse sentido, o diálogo é a essência da Pedagogia, uma vez que possibilita o pensamento crítico e promove a verdadeira comunicação. Por esses caminhos, o homem se humaniza, ação reflexiva que possibilita a comunicação com os outros para desvelar a realidade.

O diálogo produz a conscientização libertadora e transformadora. Conscientização, aqui, pode ser o caminho para a reinvenção da escola, na perspectiva de sua democratização. Freire (2014) institui o diálogo crítico e libertador como base fundadora do que chamou de conscientização. Ressalte-se que o processo de formação sustentado por uma dialogicidade permanente permite aos educandos vivenciar o mundo, mediatizados por ele, ou seja, entendendo-o, decodificando-o, intervindo sobre ele para transformá-lo. A obra "Pedagogia da 
Esperança" nos impulsiona a compreender a necessidade de coerência, expressão de nossa ação e reflexão.

\footnotetext{
[...] entre as responsabilidades que, para mim, o escrever me propõe, para não dizer impõe, há uma que sempre assumo. A de, já vivendo enquanto escrevo a coerência entre o escrevendo-se e o dito, o feito, o fazendo-se, intensificar a necessidade desta coerência ao longo da existência (FREIRE, 2014, p. 65).
}

Enquanto não se pode entender a existência humana, sem esperança e sem sonhos, a coerência com o sonho democrático se concretiza na prática educativa do professor como expressão de sua posição dialética e democrática. Pode-se destacar que o processo de construção do conhecimento não ocorre como mágica, mas exige o estudo da construção e reconstrução de conceitos; exige, ainda, paciência e o exercício do diálogo dito e feito, considerando as possibilidades do refeito.

\section{Análises conclusivas}

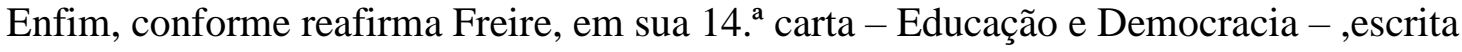
em Cartas a Cristina (FREIRE, 1997, p. 244), “[...] ensinar democracia é possível. Para isso, contudo, é preciso testemunhá-la. Mais ainda, testemunhando-a lutar para que ela seja vivida, posta em prática". Observa-se que o papel da escola é de desvelamento dessa realidade. Dessa forma a escola não se caracteriza como um espaço neutro, considerando que a prática educativa se configura como prática política.

Portanto, coloca-se para as escolas um grande desafio, a saber, o de respirar e vivenciar a democracia, construída paralelamente à luta contra práticas autoritárias no espaço escolar e, por consequência, na sociedade. Tais princípios apresentados pelo autor, especialmente a centralidade dos processos de autonomia e de liberdade, visando compreender a educação em sua dimensão política, redimensionam o conceito de democracia. Ao discuti-lo, observa-se sua importância, o que leva ao seguinte questionamento: como esse processo se dá nos espaços de educação formal? Nas práticas escolares, por vezes, são excludentes, insensíveis às diferenças, às necessidades e às suas especificidades.

Assim, Freire (2005) desafia os educadores a partilharem um grande sonho em suas cidades educativas: que as desigualdades e a discriminação diminuam. Afinal, a democracia que convive com a fome, com a miséria, que espanca em nome da própria democracia, que se constrói em detrimento da verdade é uma farsa, pois, “[...] a democracia demanda estruturas democratizantes e não estruturas inibidoras da presença participativa da sociedade civil no comando da res publica" (FREIRE, 2005, p. 15). 
Segundo Freire (2014), falar em democracia e silenciar o povo é uma farsa. Falar em humanismo e negar o humano nos indivíduos é uma mentira. Por isso, falar em atuação dos conselhos escolares é falar em relação dialógica que constrói e reconstrói o ser humano em sua relação com o outro; é considerar que cada membro do conselho é corresponsável pelo respeito e pela valorização do saber do educando e do patrimônio cultural da comunidade. Também é, ao mesmo tempo, ser responsável pela construção coletiva, solidária e corresponsável desse respeito e dessa valorização.

Analisar a relação opressor contra oprimido no espaço escolar é não percebê-la apenas no autoritarismo, mas também no silenciamento do outro, que ocorre quando o saber e a cultura dos educandos são desrespeitados, quando se negam suas origens, etnias e seu contexto social com todas as suas contribuições e história. Torna-se importante ressaltar que essa atitude antidialógica abre caminho para uma escola antidialógica, pois nega a educação, limitando as suas possibilidades.

Os princípios apresentados pelo autor e a centralidade dos processos de autonomia e de liberdade, visando compreender a educação em sua dimensão política, remetem à discussão da democracia como um conceito essencial, que demanda estruturas democratizantes e não estruturas inibidoras da presença participativa da sociedade civil no comando da República.

\section{Referências}

FREIRE, P. Educação como Prática da Liberdade. Rio de Janeiro: Paz e Terra. 1967.

FREIRE, P. Ação cultural para a liberdade e outros escritos. Rio de Janeiro: Paz e Terra, 1981.

FREIRE, P. Cartas à Cristina: reflexões sobre minha vida e minha práxis. São Paulo: Paz e Terra, 1997.

FREIRE, P. Política e educação: ensaios. 5. e d. São Paulo: Cortez, 2001.

FREIRE, P. A educação na cidade. 6. ed. São Paulo: Cortez, 2005.

FREIRE, P. Educação e mudança. São Paulo: Paz e Terra, 2008.

FREIRE, P. Pedagogia da Esperança: um reencontro com a Pedagogia do Oprimido. 16. ed. Rio de Janeiro: Paz e Terra, 2009.

FREIRE, P. Pedagogia do oprimido. 31. ed. Rio de Janeiro: Paz e Terra, 2014.

LIMA, L. C. A escola como organização educativa: uma abordagem sociológica. São Paulo: Cortez, 2003. 
LIMA, L. C. Organização escolar e democracia radical. Paulo Freire e a governação democrática da escola pública. 5. ed. São Paulo: Cortez, 2009.

SME/SP. SECRETARIA MUNICIPAL DE EDUCAÇÃO. Construindo a educação pública popular. São Paulo: Município de São Paulo, 1989.

SME/SP. SECRETARIA MUNICIPAL DE EDUCAÇÃO. Planejamento. Instrumento de mobilização popular. São Paulo: Município de São Paulo, 1992. 